\section{EDITORIALES CONFLICTIVAS Y DISIDENTES EN TIEMPOS DE DICTADURA (1966-1975)}

\author{
Jesús A. Martínez \\ Universidad Complutense de Madrid
}

\section{EDITORIAL CONFLICT AND DISSIDENTS DURING THE DICTATORSHIP (1966-1975)}

ABSTRACT: On the basis of a rich and unpublished documents from the Archives of the National Institute of Spanish book and in particular the records of the Register Publishing Company, publishers are studied those considered most troubled and dissidents by the Franco dictatorship between 1966 and 1975. Through publishing plans, financial, notarial documents, administrative... and especially police reports reveal the strategies pursued by publishers to overcome the obstacles of the system while implementing the control mechanism put in place by the Press and Printing Act of 1966, which show the apparent gap between political tolerance and greater demand for the instruments of control of print culture. Publishers conflict and dissidents demonstrated the contradictions between changes social, economic and cultural rights of Spain in the sixties and seventies and the political stagnation of the dictatorship.

KEY WORDS: Publishing; publishers; editors; culture; books; censorship; dictatorship of Franco.

El 28 de junio de 1974 la Dirección General de Cultura Popular del Ministerio de Información y Turismo elaboró una relación de editoriales conflictivas y la envió a la Dirección General de Seguridad del Ministerio de Gobernación solicitando informes sobre los antecedentes de las personas vinculadas a estas editoriales. Todas ellas habian conseguido su inscripción en el registro de Empresas Editoriales creado por la Ley de Prensa e Imprenta de 1966. Este Registro era obligatorio para desarrollar la actividad editorial y por él pasaron todas las editoriales ya existentes o creadas desde 1966, aportando necesariamente, entre otros documentos, la escritura de constitución de la sociedad, sucesivas ampliaciones de capital y modificaciones en la empresa, socios fundadores, relación de propietarios 0 accionistas, planes editoriales, patrimonio, planes financieros... y declaración por parte de los propietarios de estar en posesión de los derechos civiles y políticos, a lo que sumaba la petición de informes a la Dirección General de
RESUMEN: Sobre la base de una rica e inédita documentación del Archivo del Instituto Nacional del Libro Español y en concreto los expedientes del Registro de Empresas Editoriales, se estudian aquellas editoriales consideradas más conflictivas y disidentes por la Dictadura de Franco entre 1966 y 1975. A través de los planes editoriales, financieros, la documentación notarial, administrativa... y sobre todo de los informes policiales se desvelan las estrategias seguidas por las editoriales para superar los obstáculos del régimen y al mismo tiempo la aplicación de los mecanismo de control puestos en marcha por la ley de Prensa e Imprenta de 1966, que ponen de manifiesto el desfase entre una aparente tolerancia política y la mayor exigencia de los instrumentos de control de la cultura impresa. Las editoriales conflictivas y disidentes demostraron las contradicciones entre las transformaciones sociales, económicas y culturales de la España de los años sesenta y setenta y el inmovilismo político de la Dictadura.

PALABRAS CLAVE: Edición; editoriales; editores; cultura; libros; censura; Dictadura de Franco.

Seguridad por la Sección de Ordenación Editorial del Ministerio de Información, de quien dependía el Registro'. No todas las editoriales que lo solicitaron fueron autorizadas a registrarse y a otras les fue cancelada la inscripción, como la editorial Ciencia Nueva en el primer caso o las editoriales Estela, Halcón o Ricardo Aguilera en el segundo. Otras sufrieron tiempos de demora en la tramitación, formando parte de la estrategia de la administración para impedir su registro y, por tanto, dejándolas en una situación económica difícilmente sostenible para las editoriales. La relación de 1974 sólo incluía algunas conflictivas, pero todas tenían número de registro, y por tanto habían sido autorizadas con sus correspondientes declaraciones e informes. Pero el documento es muy significativo al recoger, según el criterio de Ordenación Editorial, aquellas empresas que, habiendo sido autorizadas, mostraban en sus actividades, o en las de su personal, signos de conflicto político para el régimen en un momento muy crítico como el del verano de 1974. 
La Ley Fraga de 1966 había intentado modernizar los mecanismos de control de la cultura impresa, pero no en claves de una supuesta apertura sino para acoplar la represión de las disidencias a los nuevos tiempos marcados por las transformaciones económicas y sociales de los años sesenta, los cambios en la estructura empresarial, las expectativas sociales y los cambios generacionales y culturales en relación con un mayor contacto con el exterior. Con ello se produjeron las transformaciones editoriales de carácter empresarial, financiero, comercial y sus expectativas para colmar una demanda en aumento y en reconversión que reclamaba todo tipo de libros y publicaciones y en este contexto se desplegó el interés por el libro político y de pensamiento crítico y la traducción de numerosas obras procedentes del extranjero. Los nuevos mecanismos de control impulsados por la ley de 1966 lograron controlar pero no taponar la multiplicación de libros y editoriales que proyectaron un sentido crítico con el régimen y entre 1966 y 1975. La difusión de libros conflictivos y las editoriales que los publicaban se convirtieron en elementos incómodos y finalmente peligrosos.

Aunque la ley de 1966 había suprimido la censura previa como dimensión teórica de una apertura del régimen en el ámbito de la libertad de expresión, en la práctica estableció fuertes mecanismos de control preventivo y punitivo de la producción editorial bajo el ropaje de la tutela administrativa $y$, por tanto, de una práctica de la censura rigurosa que los editores trataron de sortear. La ley estableció tres mecanismos de control preventivo: la posibilidad de presentar los textos a consulta voluntaria -ello invitaba a la autocensura y aliviaba la posibilidad de evitar un secuestro una vez editada la obra con el consiguiente perjuicio económico-, la obligación de un depósito previo de 6 ejemplares una vez editada la obra y la creación del citado Registro de Empresas Editoriales -y también el registro de Empresas Importadoras, para controlar la producción exterior que se pretendía publicar en España-. Los dos primeros mecanismos podían acabar en denegaciones, silencios administrativos y en secuestros. Por su parte el registro de Empresas Editoriales, obligatorio, exigía una numerosa y compleja documentación, expuesta anteriormente, que controlaba preventivamente la producción y sus protagonistas desde la creación de la empre$\mathrm{sa}^{2}$ (planes financieros, planes editoriales, accionistas...) y exigía la comunicación de cualquier cambio cada seis meses. El Registro de Empresas Editoriales no tenía sólo una dimensión administrativa para encauzar la producción editorial, sino que fue diseñado y se convirtió en sí mismo en un eficaz instrumento de control. La aplicación de la censura y de estos mecanismos de control contrastó con el barniz aperturista con el que se había presentado la ley3. $Y$ en ello se empeñó el régimen, incapaz de resolver sus contradicciones internas entre el inmovilismo, los discursos sobre una apertura y las transformaciones políticas, económicas y sociales que fueron desbordando la realidad de una Dictadura estancada en sus esencias.

El crecimiento económico y la configuración de una sociedad industrial en los años sesenta, los procesos migratorios y de urbanización, los cambios sociales, el aumento de la educación, eran aspectos de cambio incompatibles con el inmovilismo político y así la conflictividad social y la protesta política se acentuaron en la década de los años setenta, mientras el régimen se debatía entre el mantenimiento a ultranza de todos los soportes políticos en los que se sustentaba y una supuesta apertura que nunca se llegó a concretar y a plasmar antes de 1976. Y con ello el instrumento de la represión de las disidencias que, en sintonía con el inmovilismo político y el aumento de la conflictividad, se acentuó con el inicio de la década y sobre todo desde principios de 1974. Aunque el discurso del presidente del gobierno Arias Navarro ante las Cortes el 12 de febrero de aquel año se había tejido sobre la base del "aperturismo", la práctica política y las posiciones de los sectores más ultras del régimen dejaron aquella declaración en una tímida exposición de intenciones. El denominado "espíritu de abril" quedó sin contenido y ejemplificado en múltiples conflictos y situaciones como el deterioro de las relaciones con la Iglesia después de la homilía del obispo de Bilbao Añoveros, la ejecución de Puig Antich y el despliegue de numerosas detenciones y procesamientos en estos meses de 1974. Desde comienzos de años una ola de conflictividad laboral, protestas estudiantiles y manifestaciones recorrió la península, especialmente en Madrid, Cataluña y el País Vasco ${ }^{4}$. A ello se sumó un contexto internacional de reprobación de la Dictadura más vulnerable aún después del triunfo de la revolución de los claveles en la vecina Portugal en abril, y además en el mes de julio el deterioro de la salud del dictador y el traspaso eventual de poderes a Juan Carlos de Borbón y el nacimiento de la Junta Democrática de España en París como primer organismo unitario de oposición política al régimen, configuraron una situación de crisis. 
El único sintoma de cierto aperturismo en 1974, así entendido más por los sectores ultras del régimen que por los sectores críticos y de oposición, fueron los proyectos de algún ministerio y sobre todo la relativa tolerancia de la política de información y espectáculos del ministro de Información Pío Cabanillas. Pero esa tolerancia respecto a la prensa y a los espectáculos públicos no quedó verificada en la práctica cotidiana del control de libros e impresos como pone de manifiesto la preocupación por las editoriales conflictivas. De hecho la mayor permisividad con los espectáculos y una actitud más tolerante con la prensa señalaron al ministro como uno de los causantes de un cambio inadmisible para el régimen y fue cesado a finales de octubre de ese año provocando una crisis gubernamental. $Y$ con él se fue el Director General de Cultura Popular, Ricardo de la Cierva, del que dependía el Registro de Empresas Editoriales. La aparente apertura no había cuajado en el mundo editorial que siguió sujeto a los mismos procedimientos. De hecho, la iniciativa por situar las editoriales más conflictivas partió de la Dirección General de Cultura Popular y se solicitó la colaboración de la Jefatura de Información de la Dirección General de Seguridad y en la nota dirigida a Ricardo de la Cierva con las conclusiones del informe se decía: "se considera conveniente, para estímulo de los futuros trabajos, una carta del Director General de Seguridad agradeciendo la colaboración" ${ }^{\prime \prime}$. Éste es el contexto de crisis en el que se elaboró la relación de "editoriales más conflictivas".

La relación se componía de doce editoriales y se acompañaba la calificación que se adjudicaba a cada una después de los informes de la Dirección General de Seguridad:

-Editorial Ayuso: Personal desafecto.

- Editorial Castellote: Sin antecedentes.

-Editorial Alberto Corazón: Desafecto; relación con elementos comunistas.

- Editorial Fundamentos: Sin antecedentes directos.

- Editorial Artiach: Antecedentes desfavorables. Ideología comunista.

- Graficas Espejo: Antecedentes favorables.

- Editorial Akal: Algo conflictivo.

- Guadiana S.A.: Línea demócrata-cristiana, con alguna conflictividad.

- Editorial Fenicia: Sin antecedentes.

- Brais Pinto: Conflictivo.
- Seminario y Ediciones: Con personal conflictivo. Figuran los nombres de Camilo José Cela, Laín Entralgo, López Aranguren, Raúl Morodo, Dionisio Ridruejo, Prados Arrate, Ruiz Jimenez, Tierno Galván, Zayas, Mariátegui, etc. - Editorial Zero: Personal conflictivo. Pedro Ibarra Guell.

En las conclusiones del informe dirigido al Director General de Cultura Popular se calificaba a cuatro de las editoriales "elegidas según los datos obrantes en la Sección de Ordenación Editorial" como "sin antecedentes", "sin antecedentes directos" o "antecedentes favorables": CasteIlote, Fundamentos, Gráficas Espejo y Fenicia. La jerarquia continuaba con "antecedentes desfavorables", como así se tipificó a la Editorial Artiach, a lo que seguian dos editoriales con "personal desafecto": Editorial Ayuso y Alberto Corazón. Dos con los términos "algo conflictivo", señalando a Akal y a Guadiana, y finalmente las tres consideradas conflictivas: Zero, Brais Pinto y Seminario y Ediciones, añadiéndose en este último caso una relación de "personal conflictivo".

\section{Editorial Zer-ZyX: Libros ReVoluCionarios entre LA ELITE de VIZCAYA}

La Editorial Zero fue una de las editoriales más disidentes contra el régimen a finales de los años sesenta y principios de los setenta. Con su sello circularon numerosos títulos, en pequeños formatos y precios baratos, relacionados con el pensamiento político, el ensayo crítico, o las traducciones sobre el marxismo, el anarquismo y el movimiento obrero. La editorial se constituyó el 17 de diciembre de 1968 en Guecho, en la calle Telleche n. ${ }^{\circ} 11$, con un capital social de 150.000 pesetas, repartido entre sus seis fundadores con 50 acciones cada uno de 500 pesetas. Los seis socios eran Pedro Ibarra Güell (apoderado y vocal del Consejo de Administración) y su esposa Carmen Oriol (secretaria del Consejo); Ignacio Cardenal Abaitua (presidente) y su esposa Ana Cortázar, e Isidoro Delclaux

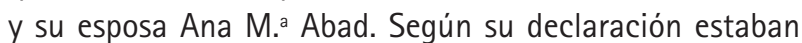
en posesión de los derechos civiles y políticos, fórmula exigida para inscribirse en el Registro de Empresas Editoriales. Presentaron la solicitud en el Registro dos meses más tarde de su constitución, el 18 de febrero de 1969, para poder iniciar su actividad de explotación del negocio editorial y de las artes gráficas. Solo nueve dias después 
se realizaron los informes de la Dirección General Seguridad, solicitados previamente por el Servicio de Ordenación Editorial $^{6}$. Y en ellos no constaban antecedentes desfavorables. Al contrario, Ignacio Cardenal, nacido en Bilbao, era considerado "afecto a los principios del Movimiento Nacional" y "educado en el seno de un familia de ideología derechista", a Isidoro Delclaux, también nacido en Bilbao, no se le conocían actividades políticas pero se señalaban tendencias monárquicas al igual que las de su familia y se hacía mención a su actividad como vicepresidente del Grupo Aquelarre dedicado al fomento del Arte y del Teatro vasco, y, finalmente, a Pedro lbarra Guell, se le calificaba de "afecto" con "excelente conducta" e hijo del banquero Pedro Ibarra Mac Mahon de "gran relieve social en Vizcaya".

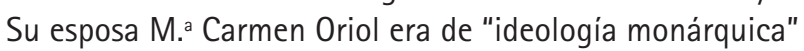
y "afecta" al régimen y sobrina del Ministro de Justicia Antonio Maria de Oriol' ${ }^{7}$. Similares etiquetas de afección al régimen o buena conducta eran para Ana Cortázar y Ana Maria Abad. Todos los componentes de la editorial y sus familias eran considerados como personas vinculadas al régimen, con ideología derechista o monárquica, y de la elite económica y social de Vizcaya. Con esas referencias, se autorizó la inscripción en el Registro, toda vez que la editorial tenía su sede en el domicilio de Ibarra-Oriol y que su plan editorial consistía en una colección de Arte y otra de educación para niños. En su plan financiero se destacaba además que "la proliferación de editoriales en España no es un obstáculo para que nuestras inversiones no sean lo suficientemente rentables, ya que lo que falta a nuestras editoriales es un espíritu de empresa, de productividad económica y máximo beneficio, pues descuidan el aspecto comercial a favor de las aspiraciones o intenciones semipolíticas que caracterizan a muchas de ellas".

La inscripción en el registro se produjo el 14 de junio de 1969, pero el inicio de sus actividades editoriales y la naturaleza de las primeras publicaciones empezaron a preocupar al Ministerio de Información. En julio de ese año ya habian denegado a la editorial la publicación de tres obras a través de sus correspondientes expedientes de censura: "Cristianos y Revolución en Latinoamérica", "Juventud contra el mundo" y "La siega". Ese mismo mes una nota sobre la editorial recogía este extremo pero insistía en que los informes y antecedentes consideraban a todos sus miembros "afectos a los principios del movimiento nacional". Pero era el inicio de una larga cadena de publicaciones denegadas hasta un total de 42 originales rechazados entre julio de 1969 y marzo de 1970, obras de Marcuse, Proudhon, Morato, Saborit, Max Nettlau, C. Díaz..., sobre el socialismo, la clase trabajadora, el movimiento obrero, anarquismo, la Internacional, sindicalismo, comunismo... hasta una biografía de Lenin o la historia del partido comunista. Desde luego saltaron todas las alarmas políticas y de la censura acerca de una editorial aparentemente afecta al régimen, pero cuyos títulos presentados eran un reto directo para el franquismo que partía de sus propias entrañas, de familias acomodadas y reconocidas socialmente en los ambientes de Bilbao. Que descendientes de importantes personajes del mundo financiero e industrial de Vizcaya y que la sobrina de un Ministro de Justicia figuraran entre los promotores de originales sobre la historia y problemas del mundo obrero eran un aldabonazo para el régimen y la demostración más palpable de sus contradicciones. En el mes de septiembre de 1969, con un verano plagado de títulos rechazados para la editorial, la Subdirección General de Información volvió a pedir informes por teléfono al Delegado Provincial de Vizcaya sobre la editorial, que contestó con los mismos informes señalando que "pertenecen a familias de una indiscutible filiación derechista... cuyos apellidos (especificaba Ibarra y Delclaux), fortuna e influencia locales son de notoriedad absoluta" y sus actividades editoriales eran inéditas en Vizcaya porque alli no habian presentado ninguna obra para su depósito, aunque mantenían contactos con grupos de teatro como "Akelarre" o el Ateneo de Bilbao.

Pero la historia de Zero estaba vinculada desde el principio a los avatares que había seguido la editorial ZYX, que había sido creada a finales de 1963 e iniciado su actividad editorial el 20 de febrero de 1964 en Madrid. Solicitó la inscripción en el Registro de Empresas editoriales el 6 de abril de 1967, pero nunca se aprobó su inscripción a pesar de las numerosas gestiones realizadas El argumento era la naturaleza de sus publicaciones que un nota informativa -años más tarde, en 1978- calificaba de tendenciosas con una producción de "obras de temas político-sociales muy avanzados, a veces rozando lo subversivo y vendiendo a precios módicos incluso en la vía pública", mientras en 1974 la descripción de las actividades de la editorial era más contundente "sobradamente conocida por su postura antirrégimen, instigadora de la clase laboral, subversiva y panfletaria". La administración practicó el silencio administrativo ${ }^{9} \mathrm{y}$, si bien Zyx presentó originales a trámite de consulta voluntaria, a lo que fue obligada como todas las 
editoriales sin inscripción en el Registro, no se le permitió seguir publicando desde 1969. Una nota informativa de 1974 situaba el nacimiento de Zero como consecuencia de la cancelación de Zyx. Aquélla empezó a editar la mayor parte del fondo editorial de esta última que quedó como empresa distribuidora. Así Zero editaba y Zyx distribuía, con el logotipo de Zero-Zyx.

Desde el verano de 1969 la editorial Zero estuvo en el punto de mira de la represión de las disidencias. La denegación de más de cuarenta obras, procedentes en parte del fondo de Zyx, en ese año y el siguiente, verificaban una situación conflictiva. La preocupación de las autoridades del Ministerio no estaba sólo relacionada con el contenido doctrinal e ideológico de las publicaciones, sino, como en las otras editoriales, por su divulgación y repercusiones sociales, favorecidas por unos formatos pequeños y baratos, de fácil manejo y precios asequibles, dirigido a un conjunto social mucho más amplio que las elites intelectuales.

En 1971 un pleito enfrentó a la administración con la editorial a raíz del intento de la publicación de la obra de Engels "El origen de la propiedad privada, la familia y el Estado". La editorial había presentado a depósito la obra, por José Miguel Oriol López-Montenegro, hermano de Carmen Oriol, pero no quedó constituido el depósito al argumentar la Dirección General de Cultura Popular que el contenido del libro no se correspondía con el plan editorial declarado y que tal obra "dentro de la producción editorial de obras marxistas, la de referencia implicaba un grave atentado contra los principios fundamentales imperantes en nuestra legislación y sociedad". Este documento iba más allá al afirmar que de la trayectoria de la editorial Zero "se desprendía con toda evidencia la desviación del plan editorial declarado en su día" y se planteaba una posible cancelación de la inscripción de la editorial. La resolución fue recurrida por la editorial en noviembre de 1971 argumentando, entre otras razones, que la obra formaba parte del plan editorial al estar dentro de las materias "Técnicas, literarias, historia, economía, sociología, arte y poesía" en las que estaba especializada la editorial, pero sobre todo el recurso apuntaba a una visita realizada al Director General de Cultura Popular, Carlos Robles Piquer, por el presidente lbarra ("Barón de Guell") y otros dos miembros de la editorial en el verano de 1969 para confirmarle el propósito de concretar el programa editorial en los libros que se iban publicando y que incluia el de Engels "sin que tampoco entonces se manifestara por el IImo. Sr. Director general que no entraba en el plan editorial dicho libro". Esta circunstancia pone de manifiesto además el periplo que realizaron muchas editoriales de la época para sortear la censura y que incluyeron gestiones de todo tipo y visitas a los responsables de la misma. Las conversaciones y correspondencia mantenidas entre Zero y Ordenación Editorial concluyeron en este caso con la retirada del recurso de alzada por parte de la editorial.

La editorial continuó con su línea de publicación disidente en 1972 y 1973. En enero de 1974 comunicaba a la sección de Ordenación Editorial la puesta en marcha de una nueva colección "La aventura del saber", compuesta por libros de filosofía y dirigida por Carlos Díaz y Gabriel Albiac y presentaban varias obras como inicio de la colección de Abbagnano, Luckas, Marcuse, Comte, Weber, Sartre y otras que abrirían la colección: Kropotkin, Mounier, Lenin, Grisoni ("Leer a Gramsci"). Esta situación se había hecho insostenible para los responsables del control de las publicaciones y del Registro. Ese mismo mes en la sede de la editorial ZYX en Madrid se encontró "un paquete conteniendo veinte ejemplares de la publicación Frente Libertario editada en Francia de contenido subversivo"10.

Al mes siguiente, en febrero de 1974, una nota informativa sobre la editorial Zero afirmaba con rotundidad que "preocupa profundamente el cariz de la producción editorial de Zero" y "si desde un principio ha constituido una de las editoriales conflictivas, últimamente su actividad se ha endurecido ideológicamente. Presenta en su última etapa -normalmente a Consulta Voluntaria- un promedio de cinco o seis expedientes diarios, no sólo conflictivos, sino en su mayoría absolutamente denegables". Las publicaciones de Zero y los depósitos a consulta voluntaria representaron un continuo quebradero de cabeza para los responsables de la censura y el registro, embarcados en un "sistemático tanteo" para el control de los libros. Claro está que los informes de la Jefatura Superior de Policía de 1974 que dieron lugar al dossier sobre "Editoriales conflictivas" ya no eran tan favorables o neutros como los de 1969 y la Brigada Central había esmerado su investigación con los responsables de ésta y otras editoriales. Pedro Ibarra Guell ya era tipificado como de "tendencia comunista", y se relatan numerosas actividades desde 1972 relacionadas con la propaganda política, la responsabilidad en distribución de libros de "tipo comunista", sus actuaciones en calidad 
de abogado y las medidas de represión ejercidas contra él, entre otros extremos. El curriculum policial había cambiado de signo. Respecto a Ignacio Cardenal se le seguia considerando persona de excelente conducta en todos los órdenes aunque la minuciosidad de las investigaciones fue bien palpable sin demostrarse ningún "hecho delictivo". La supuesta situación de afectos al régimen, basada en una equívoca deducción por la procedencia social, económica y política de sus familias, contrastaba con la existencia de una juventud inquieta, crítica, contestataria, comprometi$\mathrm{da}$, a menudo relacionada con medios católicos, curtida a finales de los cincuenta y en los sesenta con expectativas sociales, culturales y políticas muy distintas a las supuestas por la Dictadura".

A principios de 1974 esta nota informativa concluía con la intención de cancelar la editorial, "que la administración tiene en su mano la posibilidad de ordenar cuando quiera y en el momento que estime necesario". De hecho hubo una resolución del Ministerio de Información, no cursada, cancelando la inscripción, con el argumento de que "se viene comprobando que de modo sistemático Zero edita publicaciones cuyo contenido difiere sustancialmente del indicado concretamente en el plan editorial"12. La editorial pasó a engrosar la nómina de editoriales conflictivas ocupando un puesto de primer orden como pone de manifiesto el documento del mes de junio de 1974 con que se iniciaba este relato. La editorial no llegó a ser cancelada. Había contribuido a abrir las fisuras del régimen y a desvelar el conjunto de contradicciones de la Dictadura. Otras editoriales como "Ciencia Nueva" no llegaron a lograr la inscripción en el Registro porque no tenían las credenciales de Zero, al fin y al cabo sus promotores pertenecian a familias de la selecta sociedad vasca del mundo de las finanzas que no infundían al principio sospecha alguna. De hecho, el enlace Ibarra-Oriol, celebrado tres años antes de la creación de la editorial, estaba apadrinado por una representación de los condes de Barcelona y firmaron como testigos los ministros de Justicia e Interior ${ }^{13}$. Era todo un símbolo que permitió una cobertura para la publicación de obras que el régimen no supo controlar preso de sus contradicciones. En 1978 Zero solicitó modificar en el Registro de Empresas Editoriales su denominación por la de Zero-Zyx. Fue aceptada el 28 de septiembre de 1978, pero ya eran otros tiempos, en un marco de libertades que quedó verificado con la aprobación de la Constitución democrática tres meses más tarde. Ésta y otras editoriales perdieron poco a poco el sentido con el que habian sido promovidas, y Zero-Zyx tuvo que reconvertirse en una nueva etapa con mayor atención a las publicaciones literarias y años más tarde declaró pedir la suspensión de pagos, que la propia editorial situaba en "la crisis general de la izquierda y el consecuente desencanto que ha provocado un descenso del interés por parte del público". Pero ésta ya es otra historia.

\section{Seminarios y Ediciones SA (SESA). Circulos de INTELECTUALES Y PROFESORES UNIVERSITARIOS DISIDENTES}

Esta editorial reunió un nutrido inventario de intelectuales de la época, de diversa procedencia, que representó el sentido crítico y contestatario contra la dictadura, en su versión liberal, demócrata-cristiana o socialdemócrata. Algunos eran procedentes de las mismas entrañas del régimen, como el exministro de Educación Joaquín Ruiz Jiménez o el exfalangista Dionisio Ridruejo, otros jóvenes catedráticos del mundo universitario como Tierno Galván, López Aranguren o Raúl Morodo. Todos eran considerados como personal conflictivo y los informes realizados por la Brigada Central son minuciosos al respecto de todas sus actividades. Para ellos el régimen tampoco tenía un antídoto eficaz para la represión de sus actividades que se desplegaron en reuniones, manifiestos, publicaciones de libros...

La editorial había nacido el 11 de octubre de $1965^{14}$, con la iniciativa del escritor Pablo Martí Zaro, el abogado francés Jean-Yves Bouedo, y la doctora en Ciencias belga Roselyne Chenu. El 9 de marzo de 1967 la Junta general de accionistas aprobó la adaptación de la empresa a la Ley de Prensa e Imprenta de 1966, transfiriéndose las acciones de los dos socios extranjeros a dos nuevos socios, el Catedrático de Economía José Luis Sampedro y el notario Carlos M. B Bru, que se sumaron al promotor de la editorial, el escritor Pablo Martí Zaro, secretario y consejero-delegado. El capital de la sociedad era de 250.000 pesetas, correspondiendo la mayoría (125.000 pesetas) a Martí Zaro y el resto entre los dos nuevos accionistas. En aquella Junta aprobaron solicitar la inscripción en el registro como era perceptivo y así lo hicieron el 20 del mismo mes. Pero cinco años más tarde, en 1972, todavía el Ministerio de Información no había resuelto la inscripción. En esos cinco años el capital social había crecido cinco veces, hasta 3.500 .000 pesetas, y 
el primitivo núcleo de tres accionistas se había convertido en una larga nómina de 87 pequeños accionistas que recogía un importante repertorio de intelectuales, escritores y catedráticos de Universidad que desplegaban su sentido crítico y disidente respecto al régimen.

El 18 de agosto de 1966 la editorial había nombrado un Consejo Asesor Técnico -sin parangón en otras editoriales de la época- formado por 14 miembros y encargado de la orientación de las publicaciones. Ese Consejo sería la cantera con la que se alimentó la empresa de nuevos socios y Consejos de Administración. En él estaban Sampedro y Bru que, al año siguiente como se ha visto, formarian parte del triunvirato de accionistas y del Consejo de Administración. Además estaban el arquitecto Fernando Chueca Goitia, el médico Domingo García Sabell, los escritores Buero Vallejo, José Luis Cano, Lorenzo Gomis, Mariano Manent, Dionisio Ridruejo y José María Castellet, y los catedráticos y doctores Laín Entralgo, Tierno Galván, López Aranguren, y Javier Marías, un selecto elenco de la intelectualidad española de la segunda mitad del siglo XX. El proyecto editorial se asentaba en tres colecciones. Anthropos, sobre teoria sociológica, Colección Symposium, para reedición de clásicos del pensamiento social y político, y Cuadernos de Documentación sobre cuestiones éticas y sociales, y ya había publicado fuera de colección obras de Caro Baroja, Daniel Suerio, García San Miguel o José Luis Abellán. La naturaleza de las publicaciones y el perfil intelectual y político de los miembros de la editorial y del Consejo resultaban muy incómodos para el régimen, toda vez que sólo unos meses más tarde de solicitar la inscripción, en febrero de 1968, la editorial había duplicado el capital social ${ }^{15}$ con el concurso de 14 nuevos accionistas que aportaron 15.000 pesetas cada uno y que no eran otros que los miembros del Consejo Asesor, además de la incorporación de otros dos catedráticos de Universidad como José Antonio Maravall y Prados Arrate y el doctor en Ciencias Exactas Carlos Santamaría. Los informes sobre la lista de los 17 accionistas desvelaban trayectorias preocupantes y conflictivas para el régimen, situaban a la mayoría vinculados al club internacional PEN ${ }^{16}$ y a la Sociedad Editorial de Escritores ${ }^{17}$, y las palabras liberal demócrata, demócrata cristiano, socialdemócrata, socialista... salpicaban la definición política de sus componentes. Sampedro era calificado de "tendencia marxista", Castellet como autor del libro separatista "Antología de la poesía catalana del siglo XX", y a todos como participantes en actos contrarios al régimen, además de la alusión a la separación de sus cátedras de López Aranguren y Tierno Galván en 1965, la de este último convertida en "semillero de ideas contrarias al régimen".

En abril de 1972 el capital social de la editorial era de 3.500 .000 pesetas, que aumentó sucesivamente hasta 7 millones de pesetas en 1973 y alcanzó 12 millones en 1976. El eco de la editorial era manifiesto y porque alrededor de ella habian confluido un nutrido grupo heterogéneo pero bajo la vitola de intelectuales de izquierda cuyos actos, escritos, manifiestos, reuniones abrían constantes fisuras en la crisis del régimen. En abril de 1972 los accionistas eran 87. Se habian sumado aportando capital, entre otros (con más de 50 acciones) Gonzalo Armero, Luis Asensio, Carlos Blasco de Imaz, Íñigo Cavero, Rosario Fernández de la Cancela, Antonio Menchaca, Carlos Zayas..., y con menor aportación de capital, pero con una participación muy significada, se incorporaron Abellán, Caro Baroja, Díez del Corral, José Esteban, Paulino Garagorri, García Añoveros, García San Miguel, Raúl Morodo, Antonio Tovar y también, significativamente, Joaquín Ruiz Jiménez.

A mediados de 1974 la Brigada Central de Información realizó numerosos informes relacionados con los miembros de SESA como respuesta al oficio de "Editoriales conflictivas". De los 87 accionistas figuraban 21, considerados más conflictivos 0 , si se quiere, más activos. Respecto a anteriores informes éstos eran muy completos y recogian la biografía de los informados y el seguimiento minucioso de todas sus actividades. Todos ellos tenían una trayectoria de protestas y actividades críticas con el régimen, a través de reuniones, conferencias, seminarios, escritos, manifiestos, apelando a la suavización de la censura o a la libertad de expresión, la libertad de detenidos y la amnistía, la reivindicación de un sindicalismo autónomo, la protesta contra el proceso de Burgos en 1970, la solicitud de la libertad de estudiantes después de los sucesos de 1956, la asistencia en algunos casos a la reunión de Munich de 1962 con el castigo de exilio, la firma de escritos para la liberta de Onetti o la celebración de Homenajes a Antonio Machado, Celaya...

Entre los expedientes más densos figura el de Enrique Tierno Galván, apartado de su Cátedra de Derecho Político en 1965 y firmante de todos los manifiestos contra el régimen. Detenido y procesado por sus actividades de ideología socialista en 1975 le situaron como el artífice 
del Partido Socialista del interior, y en continuo contacto con socialistas como Luis Gómez Llorente y Miguel Boyer, y muy relacionado con el movimiento europeo. Fue defensor de encausados ante el Tribunal de Orden Público y realizó múltiples conferencias y actividades hostiles al régimen invocando la libertad de prensa o la amnistía. También el de Ruiz Jiménez, apeado del Ministerio de Educación después de la revuelta estudiantil de 1956, y quedó calificado como liberal demócrata" o "demócrata-cristiano", con actitudes de "franca hostilidad al régimen". Era fundador de la Editorial Guadiana y sobre todo de "Cuadernos para el Diálogo" en 1966, que llevó "una incesante campaña de crítica desfavorable para las actuaciones del Estado". Defendió causas ante el Tribunal de Orden Público como la de Marcelino Camacho, líder de Comisiones Obreras. También se realizaron con esmero informes de Laín Entralgo (Rector de la Universidad Central en 1956), considerado desde 1966 "demócrata liberal", "formando parte de grupos intelectuales izquierdistas hostiles al régimen"; López Aranguren, separado de su cátedra en 1965 y de "tendencia socialdemócrata"; Fernando Chueca Goitia, representando a los intelectuales de izquierdas que quisieron construir un PEN club español, y relacionado con Tierno, López Aranguren, Laín y Ridruejo. Sobre este último se descargaban varias acepciones políticas, entre ellas la de socialdemócrata y en todo caso "liberal extremista con la finalidad de liquidar el régimen", en contraste con sus orígenes vinculados a Falange hasta 1942, pero que años más tarde había sido sujeto de las prácticas de represión por sus disidencias: confinado en Ronda, detenido en los sucesos estudiantiles de 1956 o exiliado después de la reunión de Munich. Para terminar, se referían a Julio Caro Baroja ("intelectual de izquierdas de tendencia socialdemócrata"), Camilo José Cela con varias actividades de protesta contra las sanciones de estudiantes, la censura y la pena de muerte; Julián Marías, el discípulo de Ortega de "marcada tendencia izquierdista"; el catedrático de Economía Prados, asistente en Munich y participante en la protesta contra el juicio de Burgos como otros; el joven Raúl Morodo, "brazo derecho de Tierno" y vicepresidente del Partido Socialista en el Interior, y Carlos Zayas, colaborador de "Cambio 16" y perteneciente al "socialismo avanzado". Este repertorio es una muestra de las dimensiones de protesta de los intelectuales críticos contra el régimen y que utilizaron las dotes de la palabra, la escritura y la enseñanza como instrumentos para acabar con él. El perfil y las actividades de estos 87 accionistas comprometidos pusieron en dificultades a las autoridades del régimen incapaz de controlar un movimiento que en realidad tenía mayor alcance.

La editorial había presentado a consulta previa todos los originales de las obras, como era obligatorio para aquellas empresas que no hubieran obtenido autorización en el Registro. En 1972, solicitando una vez más la resolución de la inscripción en el Registro, se comprometió a continuar sometiendo a consulta voluntaria previa todas las obras aún después de que hubieran obtenido el registro. Este compromiso, como el que realizaron otras editoriales disidentes como Edicions 62, desbloqueó la actitud del Ministerio y el registro fue autorizado el 13 de noviembre de 1972 (1071/72), cinco años después de haberlo solicitado. Había sido la misma táctica empleada por el Ministerio y su Sección de Ordenación Editorial con aquellas editoriales que contenían elementos de conflicto: la dilación administrativa, apelando a la falta de documentación o el silencio administrativo. Seminarios y Ediciones, dos años más tarde de su inscripción, seguía siendo considerada una de las editoriales más conflictivas.

\section{Brais Pinto y la edición en gallego}

Es otra de las editoriales calificadas de conflictivas. Sus dimensiones y naturaleza son distintas a las anteriores editoriales. Fue creada ya en la década de los años setenta y se trataba de una pequeña empresa con cinco accionistas. Su constitución se realizó el 26 de junio de 1972 por Cesar Arias Rodríguez, empleado, Ramón Valenzuela Otero, licenciado en Filosofía, Enrique Aller López, abogado, Bautista Alvárez Rodríguez y Raimundo Patiño Mancebo, empleado, con una capital de 500.000 pesetas, del que desembolsaron un $25 \%$. Arias y Aller eran los encargados de llevar la gestión de una sociedad que tenía por objeto la edición de libros, fotonovelas y comics en lengua gallega. El trabajo en la empresa lo realizarian los socios, sin acudir a contrataciones.

El 7 de marzo de 1973 la Dirección General de Cultura Popular solicitó informes de los socios. Todos figuraban sin antecedentes, excepto Enrique Aller para el que se elaboró un informe independiente. En este caso sólo figura desde 1970 con el impedimento para obtener el pasaporte o el certificado de buena conducta sin consultar a la Dirección 
General de Seguridad. Las razones quedaron expuestas en un informe de 1974, por sus actividades contestatarias como estudiante de la Facultad de Ciencias Económicas de Santiago de Compostela. En febrero de 1974 le fueron cancelados estos antecedentes. Una nota manuscrita en el expediente refería ver los antecedentes de Enrique Aller antes de la resolución.

En mayo de 1973 en un escrito la editorial se comprometía a enviar todos los originales a consulta previa voluntaria y argumentaba no contratar con autores hasta estar la empresa en el Registro. Su plan editorial era la publicación sobre temas gallegos en general y traducciones de otros idiomas. En el mes siguiente, 7 de abril de 1973, quedó registrada la editorial, pero como ocurriera en otras ocasiones la decisión dependia de gestiones personales o influencias en los centros de poder. Ese mismo día el Director General de Cultura Popular se interesaba por la situación del trámite y pedia al Servicio de Ordenación Editorial información sobre el asunto "dado que me piden información desde la secretaría de la Dirección General de Radiodifusión y Televisión". En este caso la solicitud de los DNI de los socios y de la escritura notarial con el capital de la sociedad fueron trámites que quedaron resueltos enseguida a diferencia de los obstáculos administrativos que se convirtieron en infranqueables para otras editoriales.

Sin embargo, el carácter de conflictividad de la editorial quedó puesto de manifiesto con los informes de 1974, ya que tres de sus miembros que en 1973 carecian de antecedentes, en 1974 desvelan una actividad política crítica con el régimen y sus horizontes de autonomía y libertad de Galicia. Los tres eran del Club Amigos de la UNESCO, y estaban relacionados con distintas actividades culturales y políticas del galleguismo. Bautista Alvárez fue Secretario del Seminario Cultural Gallego y era considerado dentro del grupo "galleguista-marxista", reclamando para Galicia autonomía económica, cultural y política. Ramón Valenzuela había pertenecido antes de la guerra civil al Partido galleguista, y en Buenos Aires fue bibliotecario de la Federación de Sociedades Gallegas, miembro de la Comisión de Cultura del Centro Gallego y presidente del Ateneo "Curros Enríquez". Autor de libros en gallego era considerado "izquierdista gallego". Y Raimundo Patiño era considerado igualmente de tendencia galleguista y relacionado con elementos de la oposición.

\section{Guadiana y la familia Camuñas. La Democracia Cristiana}

Un sector de la democracia cristiana se agrupó en torno a la Editorial Guadiana. Antes se había creado "Cuadernos para el Diálogo" impulsada por Joaquín Ruiz Jiménez, que también participó como fundador en Guadiana, o Seminarios y Ediciones. Además, los mismos componentes de Guadiana formaban parte de las editoriales Al-Borak y Ediciones 99. La editorial "Guadiana de Publicaciones, sociedad anónima" (Guadisa) fue creada el 3 de octubre de 1967, con un capital social de 1.500 .000 pesetas $^{18}$. El otorgamiento de la escritura estaba encabezado por Ruiz Jiménez, liderando la paternidad ideológica del proyecto, y lo completaban Francisco Sintes Obrador, profesor, Ignacio Sancho Rosa, abogado, Julio Rodríguez Aramberri, Doctor en Derecho, y la familia Camuñas: Antonio Camuñas Paredes y sus hijos Ignacio, Jaime, José Antonio y Francisco Javier Camuñas Solís. Los principales accionistas eran Ignacio Sancho Rosa con 500 acciones, Antonio Camuñas con 400 e Ignacio Camuñas y Julio Rodríguez con 200 cada uno; el resto habían suscrito 50 acciones. Todos ellos formaban además una Junta de Fundadores para "velar por la permanencia de los fines ideológicos de la sociedad", algo excepcional en la creación de una empresa editorial al escriturarse de manera tan contundente la vinculación expresa de las actividades editoriales con la naturaleza ideológica de la sociedad. De hecho, en los informes individualizados realizados por la Brigada Central de Información, la caracterización política como demócrata cristianos de algunos miembros del Consejo de Administración quedaba deducida por el hecho de pertenecer a Guadiana y no al revés.

La solicitud de inscripción en el registro la realizó Ignacio Camuñas el 31 de octubre de 1967 y sólo ocho días más tarde era autorizada. En este caso no hubo dilaciones administrativas, ni solicitud de documentación incompleta como mecanismos utilizados por la administración para bloquear o impedir el registro de muchas empresas editoriales sospechosas. En este caso no hubo petición de informes, bastó con un certificado del mismo día de la solicitud en que se manifestaba que los socios fundadores estaban en pleno ejercicio de sus derechos civiles y políticos. Su plan editorial era muy genérico, con obras de todo tipo: literatura, economía, religión, ensayo, historia, técnica... pero afirmaban ese día que no habian comenzado las actividades, ni existía ningún título publicado, ni había 
concreción de autores o de títulos. El plan editorial no aventuraba ninguna publicación ni desvelaba inicialmente publicaciones consideradas conflictivas. El local arrendado en la calle de Velázquez de Madrid era la sede de una empresa que tenía como patrimonio 1.500 .000 pesetas de los socios fundadores. Pero sólo un mes más tarde de la inscripción, el 29 de diciembre de 1967, se ampliaba el capital en el doble, hasta 3 millones de pesetas, suscrito en parte por algunos fundadores - principalmente por Antonio e Ignacio Camuñas- y por nuevos socios, sobre todo Pablo Varela, José Luis Mora y Víctor M. Carrascal, que pasaron a ser consejeros, mientras en 1968 Antonio Camuñas ocupaba la presidencia. Las dimensiones de la editorial aumentaron y también las sucesivas ampliaciones de capital: 1 millón en 1970, 2 millones en julio de 1971 y otros dos millones en octubre de 1972, con lo que el capital social se había elevado en esta fecha a ocho millones de pesetas. Aunque se fueron integrando diversos personajes en el Consejo de Administración, los suscriptores de las sucesivas ampliaciones fueron siempre los miembros de la familia Camuñas y Victor M. Carrascal, además de Joaquín Ruiz Jiménez que, con menor capital, representaba el testimonio de ser el referente intelectual de la empresa.

La actividad de la editorial empezó a ser incómoda para las autoridades. De hecho se situaba a Guadiana como una editorial que publicaba "revistas de línea progresista". En 1971 la Dirección General de Cultura Popular procedió a instruir un expediente sancionador a la editorial, con una multa de 50.000 pesetas, por editar la segunda edición de la obra Celtiberia show de Luis Carandell, con el argumento de no haber realizado un depósito previo de 6 ejemplares como era preceptivo. El recurso de alzada fue desestimado por el Ministerio de Información y también el recurso contencioso-administrativo, presentado en nombre de la editorial por José María Gil Robles Quiñones, en un fallo del Tribunal Supremo de octubre de 1973.

En 1974 la calificación de la editorial era de personal algo conflictivo, y la tipificación política quedaba inequívocamente asociada a la democracia cristiana. El crecimiento de la editorial y de sus miembros llevó a la elaboración de 12 informes. El impulsor de la editorial era Ignacio Camuñas, presentándole como un personaje muy significado de la democracia cristiana, de tendencia "izquierdista", muy activo, que presidía en aquella fecha además de Guadiana, Al-Borak, y era consejero delegado de Ediciones 99, secre- tario del Centro de Estudios de problemas contemporáneos hasta 1973 y promotor de "Nueva Generación SA de Estudios y Actividad". El otro miembro que en 1974 llevaba el rumbo de la editorial era el secretario Victor Manuel Carrascal, al mismo tiempo secretario de Al-Borak y de Ediciones 99. Los fundamentos cristiano-demócratas de la editorial en general eran compatibles con otras tendencias políticas supuestas o deducidas por las autoridades en los informes. Junto a miembros etiquetados de demócratas cristianos como Francisco Sentis o Fernando Asua Alvárez, se situaba a otros socios: "cierta tendencia monárquica" de Luis Guillermo Perinat, sin significación política (Víctor de la Serna, periodista), falangista y "afecto al régimen" (Ignacio Sancho Rosa) o Nicolás Franco, presidente de "Faces" (promotora del diario "Madrid") y Consejero Nacional del Movimiento. Particular atención se dedicó a İ̃̃igo Cavero, abogado, de "tendencia monárquica y liberal dentro del sector demócrata cristiano", vinculado a José María Gil Robles, miembro de la Asociación Española de Cooperación Europea y del grupo "Unión Española", señalándose su participación en la reunión de Munich de 1962 y firmante (junto a José Federico Carvajal, Alvárez de Miranda, Ruiz Gallardón) para que el Colegio de Abogados solicitara la derogación del decreto de 1960 sobre juicios por rebelión militar. En 1969 también pasó por el Consejo de Administración Enrique Miret Magdalena, y entre 1970 y 1971 Manuel Jiménez de Parga, Juan Dexeus y Trías de Bes y Marcelino Oreja. En la editorial coincidieron además, no como socios ni consejeros sino como autores, una larga lista de jóvenes intelectuales de diversos campos como Adolfo Marsillac, Manuel Summers, Amando de Miguel, o López Aranguren.

Esta red de editoriales demócratas cristianas era una pieza más del impulso editorial que había desbordado las posibilidades de control de la Dictadura.

\section{OtRAS EDITORIALES DISIDENTES Y CON PERSONAL DESAFECTO}

Esta terminología común en el régimen, "desafecto", servía para describir un grado menor de peligrosidad sobre las actividades calificadas de conflictivas. Una larga lista de editoriales eran descritas con esta denominación, y fue con la que el informe de 1974 señalaba a la Editorial Ayuso 
y a la Editorial Alberto Corazón. También fue utilizada la etiqueta de "antecedentes desfavorables" aplicada a la editorial Artiach o el rótulo de "algo conflictivo" con el que calificó a la Editorial Akal. Éstas eran editoriales de muy reciente creación y de carácter personal. Estaban vinculadas a sus fundadores, únicos socios y administradores.

La editorial Ayuso ${ }^{19}$ era una empresa personal, cuyo fundador, director y propietario era Jesús Ayuso, que regentaba la Librería Fuentetaja en la calle de San Bernardo de Madrid. Solicitó la inscripción el 17 de junio de 1969 argumentando estar en posesión de los derechos civiles y políticos, con una autofinanciación suficiente, y con un plan editorial muy genérico de novelas, divulgación científica y artística y ensayos o manuales de historia, economía, filosofía... Una nota posterior de Ordenación Editorial exponía que fueron solicitados antecedentes unos días más tarde y que, como no eran desfavorables, se autorizó la inscripción el 14 de octubre de 1969. La naturaleza de las publicaciones de la editorial provocó una nueva petición de antecedentes en junio de 1974 y la respuesta de la Dirección General de Seguridad reiteró la carencia de antecedentes, pero esta vez con un seguimiento minucioso que llevó a la conclusión de que se trataba de "personal desafecto" que, aunque no se le conocían actividades políticas, en su librería se exponían obras de "matiz político social" de varias editoriales (Ciencia Nueva, Seix Barral...) de "tendencias marxistas o izquierdistas". Ésta fue la referencia para que la Sección de Ordenación Editorial concluyera en una nota el 25 de junio de 1975 en la que a pesar de carecer de antecedentes negativos se le consideraba "como desafecto al régimen y con implicaciones con grupos y personas de dudosa ideología", y lo relacionaba con la producción editorial de 1974 y 1975, con muy pocos títulos pero en gran parte dedicadas a las obras de Marx, Engels y Lenin. En plena crisis de la Dictadura ejemplos como éste desvelan que los mecanismos de modernización de la censura introducidos por la Ley Fraga de 1966 estaban siendo desbordados a la altura de 1974.

Similar situación de empresa individual fue la de Alberto Corazón Climent, editor, dibujante y grafista, autor de portadas de numerosos libros, como los de la Editorial Ciencia Nueva. Con sede en la Plaza Mayor de Madrid y un capital de 500.000 pesetas, solicitó la inscripción en julio de 1968 $y$, previo informe policial sin antecedentes, fue inscrita en el Registro en septiembre del mismo año. En 1974 sin embargo la minuciosidad de los informes desvelaban actividades contestatarias y de protesta contra el régimen desde $1967^{20}$. Otro ejemplo lo constituye Artiach Editorial ${ }^{21}$, empresa individual de José Luis Artiach que solicitó la inscripción en el registro el 19 de junio de 1969, pero esta vez con antecedentes desfavorables relacionados con la revuelta estudiantil, según un informe de julio de 1969, lo que dilató el proceso de inscripción hasta quedar archivado el expediente en 1977. Que el Ministerio de Información se ocupó del expediente lo devela una nota de febrero de 1970 de la Subdirección General de Ordenación Editorial interesándose por el trámite, pero nunca llegó a autorizar la inscripción, con el argumento burocrático de falta de documentación, una estrategia recurrente para impedir la inscripción, como ocurriera con la Editorial Ciencia Nueva. El plan editorial era amplio y destacaba diversas obras, entre ellas varias en francés, en un plan preliminar con autores como Levi Strauss, Paulov, Radcliffe-Brown, Kant, Eisenstein, Plejanov... pero los criterios de la administración para la autorización registral siguieron siendo sobre todo las tendencias políticas de los promotores de las editoriales y sus actividades, por encima de planes editoriales genéricos, lo que había llevado a la autorización inmediata de Zero o a la dilación permanente de Ciencia Nueva. En 1974 Artiach reunía actividades de protesta desde 1966, sobre todo en el ámbito estudiantil, que no se reproducen aquí, y era calificado de "persona de ideología comunista", lo que bloqueó definitivamente la inscripción.

Por su parte Akal Editor ${ }^{22}$, empresa individual de Ramón Akal, en Madrid, solicitó inscripción en el registro el 17 de febrero de 1972 y quedó autorizada tres meses después. Un informe de 1971 manifestaba que el editor carecia de antecedentes desfavorables. El plan editorial comprendía colecciones de Enciclopedias, Colección Mundial (Arte, literatura, historia....), Colección Historia en imágenes, Colección Práctica, Colección Nuestro Mundo (infantil), a lo que sumó en 1973 la colección Arcalanga sobre temas gallegos. En el informe de 1974 se reflejan actividades como firmante de escritos para la abolición de la pena de muerte o la amnistía para delitos políticos. La conclusión era un editor "algo conflictivo". En noviembre de 1975 constituyó el preceptivo depósito de ejemplares de cuatro obras "El espectáculo de la huelga, la huelga del espectáculo", "Internacionalismo proletario", "Sobre internacionalismo proletario" y "Fanny Hill", poniéndose en marcha otro de los mecanismos del control de la administración: 
la amenaza de una denuncia judicial y, por lo tanto, la anulación voluntaria de los depósitos y el compromiso a no difundir ejemplares. La comprobación de un mayor número de ejemplares existentes que los declarados en el depósito concluyó con un expediente administrativo. La empresa Miguel Castellote Editor ${ }^{23}$, también individual, fue calificada de conflictiva en 1974, sin que constaran antecedentes en 1969 y 1974, y fue inscrita en julio de 1970, pero a finales de año habían sido denegadas ya tres de sus obras sobre economía, política y filosofía, de Kuczinski, Hugo y Voltaire, respectivamente. Por su parte la Editorial Fundamentos SA ${ }^{24}$, constituida en Madrid en abril de 1970, solicitó la inscripción al mes siguiente y fue autorizada en julio de ese año, con un capital social de 100.000 pesetas suscrito por tres miembros de la familia Serraller lbáñez y con un plan editorial como editorial pedagógica. En 1974 un informe sobre la editorial expresaba la inexistencia de informes desfavorables de sus miembros, excepto el de un miembro de la familia incorporado a la empresa en 1974 con actividades contestatarias, y sobre todo se señalaba que las publicaciones eran de "clara tendencia marxista" planteándose la posibilidad de que se llegase a cancelar la inscripción.

Las editoriales disidentes fueron muchas más que no estaban incluidas en el documento de 1974. De hecho se desestimaron 174 solicitudes en el Registro de Empresas entre 1966 y 1975. El caso de estas empresas está representado por Ciencia Nueva, constituida en Madrid en 1965, solicitando la inscripción en 1967. Quedó desestimada en marzo de 1969, coincidiendo con el estado de excepción de ese año, con argumentos de falta de documentación acerca de los derechos civiles y políticos de sus miembros y datos sobre el patrimonio. Se trató de un proceso permanente de negociación entre la editorial y el Ministerio de Información para autorizar un registro que todavía estaba pendiente en 1972 y que nunca llegó a ser resuelto. Las razones de fondo eran los antecedentes de sus miembros y el proyecto editorial. Eran jóvenes universitarios con participación en actos de protesta calificados de elementos "filocomunistas" cuando no la militancia en el Partido Comunista, y su proyecto "para contribuir a la renovación de la cultura española" tenía un carácter divulgativo que el régimen trataba de impedir. De hecho, en las prácticas de la censura del régimen en estas fechas importaba menos el carácter doctrinal de los textos que las posibilidades de divulgación que tuvieran. La desestimación y las dilacio- nes administrativas se completaron por la denegación de publicación y secuestros de obras de forma sistemática. La oposición mediante la actividad editorial de la nueva savia intelectual y crítica con el régimen fue mediatizada por el control de las autoridades del régimen expresando la contradicción con una aparente tolerancia y apertura de la ley de $1966^{25}$.

Otras editoriales pertenecientes a organizaciones muy significadas, como la católica HOAC, que solicitó su inscripción en 1967, estuvo esperando la autorización en un proceso que se dilató hasta 1975 con el argumento de falta de documentación. Había contado Ordenación Editorial con informe policial y expedientes de censura. En 1975 quedó anulada la primera solicitud y finalmente quedó inscrita en el registro en ese mismo año ${ }^{26}$. Otro ejemplo de tramitaciones interminables, formando parte de la estrategia de la administración, fue el de una importante editorial de Cataluña, Edicions 62, constituida en 1963 y que solicitó la inscripción en 1967. Pero la tipificación política de sus miembros y la publicación de libros en catalán como primer objetivo, llevó a numerosas dilaciones -varios años de "tramitación"- y al esfuerzo de José María Castellet -catalogado como de ideas "filocomunistas"- por conseguir la inscripción que finalmente acabó consiguiendo a costa del compromiso de seguir presentando todos los textos a consulta voluntaria ${ }^{27}$. Ese compromiso también lo realizó la Editorial Nova Terra. Otras editoriales sufrieron la cancelación de su inscripción en el Registro, lo que equivalía a poner en serias dificultades, sobre todo económicas, a las editoriales. Es el caso de otra importante editorial catalana, Editorial Estela, creada en 1958 para la divulgación de textos católicos, en castellano y catalán, que representó uno de los procesos donde se manifestó con mayor endurecimiento la política censora del régimen. Se trataba de un editorial con un capital de 6 millones de pesetas, 35 accionistas, presidido el Consejo de Administración por Jaime Carner, con un fondo de 700 títulos -el 80\% de carácter religioso-, con la publicación de 130 títulos anuales, 30 de ellos en catalán, con 22 trabajadores en plantilla y relación con 709 firmas extranjeras con contratos de publicación. El 29 de mayo de 1971 el Ministerio, a propuesta de Ordenación Editorial, canceló la inscripción, argumentando la publicación de títulos que no se correspondían con el plan editorial de "contenido subversivo e incitación a la revolución social". En 1970 y 1971 se habian denegado varias obras a consulta voluntaria (6 de 19 presentadas), varias 
con silencio administrativo y dos secuestros, en concreto "Historia del primero de mayo" y "Los que nunca opinan". Entre las denegadas estaban "Autopista" de Perich o "La revolución estudiantil". No sirvió el informe que envió la editorial, insistiendo en la actitud flexible y dialogante que siempre había tenido la editorial con el Ministerio, aludiendo a contactos telefónicos y personales. En este informe se hacía un balance de las consecuencias económicas (costes de libros en fabricación, contratos en vigor, deudas a proveedores, desempleo...) y culturales, dado el prestigio nacional e internacional de la editorial, que suponía la cancelación, al dejar abocada la empresa al cierre. Y ése era el objetivo del procedimiento. El propio informe de la editorial descubría conversaciones con el Ministerio en el que éste le manifestaba un endurecimiento político incluido el ámbito editorial y le hablaba de otras razones distintas a la excusa de no respetar el plan editorial. Uno de sus miembros había sido definido por las autoridades como "enemigo del régimen". Formaba parte de una política de mayor alcance. La utilización de un procedimiento administrativo podía bloquear una editorial con una importante proyección divulgativa y se convertía en un importante instrumento de control del mundo editorial. La editorial puso un recurso de alzada, pero el objetivo del Ministerio provocó el cierre de la empresa. Algunos de sus miembros pusieron en marcha su sucesora, Editorial Laia, creada en 1971, que solicitó la inscripción en ese año pero no la logró hasta 1974 con la condición de comprometerse, como había hecho Edicions 62, a presentar a consulta voluntaria todos los ejemplares que pretendiera publicar ${ }^{28}$.

También es paradigmático el caso de cancelación del registro de la editorial Halcón, empresa individual de José María Alonso Alcón, inscrita en mayo de 1968. No sirvió el recurso de alzada ante el Ministerio de Información, ni el recurso contencioso-administrativo, ya que el 19 de octubre de 1970 el Tribunal Supremo ratificó la cancelación con el argumento de que las obras presentadas por la editorial en 1968 y 1969 no se atenían al plan editorial presentado. De las 23 obras presentadas en 1968, 8 habian sido denegadas (textos de Bakunin, Engels, Trotsky,
E. Guevara, Guerin... sobre anarquismo, socialismo...), 4 en silencio administrativo (obras de Marx...) y 4 denunciadas a la fiscalía ("El Capital" de Marx, Cartas de Che Guevara, "Contrarrevolución en Cuba" de Raúl Castro, Constitución de la CNT), y en 1969 de las 13 obras presentadas 9 fueron denegadas y a una se aplicó el silencio administrativo. El argumento de la falta de relación entre el plan editorial y las obras publicadas fue muy recurrente para la cancelación del registro, que suponía "graves e irreparables perjuicios económicos" para la empresa. Pero la justificación se asentaba paradójicamente en la garantía del ejercicio de las "libertades y derechos que regula esta Ley (1966) y sancionará cualquier actividad contraria a ello singularmente cuando intente deformar la de la opinión pública" y en que los libros denegados o denunciados "tanto por su contenido en sí, como por su finalidad exceden dentro de un criterio amplio del lector medio..." superaban los límites del plan editorial general ${ }^{29}$. Para el régimen los criterios de denegación, silencio o denuncia de libros no eran sólo el de su contenido doctrinal, sino sobre todo sus posibilidades de difusión y repercusión social con el eco que podrían producir, no en las minorías ilustradas, sino en el conjunto de una opinión pública que podría ser deformada.

El mundo editorial que despertó en los años sesenta y setenta fue muy heterogéneo y con naturaleza, objetivos y estrategias muy dispares como respuestas a las transformaciones sociales y económicas, pero una larga serie de editoriales -que no se reducen a las aquí mencionadasdesplegaron un sentido crítico, comprometido políticamente, y contribuyeron a abrir fisuras en un régimen que, si bien reconvirtió y reforzó los instrumentos de control desde 1966, se vio poco a poco desbordado por los protagonistas de la difusión de la cultura impresa. La producción editorial fue un instrumento de las actitudes y propuestas disidentes contra un régimen que quiso garantizar su control, pero las editoriales fueron una de las piezas culturales y políticas que desvelaron sus contradicciones y el desfase entre la realidad de las transformaciones sociales, económicas y culturales y las inmutables estructuras de poder de la Dictadura. 
1 El Archivo del Instituto Nacional del Libro Español (INLE) donde se encuentra toda esta información, recogida en expedientes de más $500 \mathrm{em}$ presas editoriales entre 1966 y 1975 , permanece aún inédito y es la base documental manejada en el Proyecto de investigación sobre "La política del libro y la industria editorial entre 1966 y 1976", que desarrolla el Grupo de Investigación de la Universidad Complutense "Historia de la cultura impresa en España".

2 Esta información ha permitido estudiar la historia de las empresas editoriales creadas antes o después de 1966, incluso algunas como Espasa-Calpe, Revista de Occidente, Labor..., nacidas antes de la guerra civil, al exigirse las escrituras de constitución de las sociedades y sus modificaciones. Además la exigencia de las relaciones de accionistas con sus participaciones y las escrituras de las sociedades de todo tipo, incluidos algunos bancos, como accionistas de las empresas editoriales, ha permitido reconstruir el entramado financiero y empresarial de la producción editorial. Todo ello forma parte de un estudio sobre la historia de la edición y de las empresas editoriales durante la Dictadura de próxima publicación.

3 Sobre la práctica de la censura y de la aplicación de estos mecanismos de control -informes de censores y actuaciones del Registro de Empresas Editoriales- véase la Tesina de Licenciatura realizada bajo mi dirección por M. ${ }^{a}$ Carmen Menchero de los Ríos, La Ley Fraga y la censura editorial: 1966-1975, Universidad Complutense de Madrid, 1994, quien consultó por primera vez parte de los fondos del Registro de Empresas Editoriales, cuando todavía estaba el registro en su último año de funcionamiento (1993). Sobre la censura de esta época los ya clásicos estudios de Manuel L. Abellán, Censura y creación literaria en España (1939-1976), Barcelona, Península, 1980; y Cisquella, G.-Erviti, J. L. y Sorolla, J. A., Diez años de represión cultural: la censura de libros durante la ley de prensa (1966-1976), Barcelona, Anagrama, 1977.

4 Pere Ysas y Carmen Molinero, en Historia de España, siglo XX (19391996), dirigida por Jesús A. Martínez, Madrid, Cátedra, 1999, p. 234.

5 El informe está reproducido en todos los expedientes de las editoriales señaladas como las más conflictivas. Respetamos el orden de la relación y la tipificación realizada.

6 La petición de informes policiales fue muy frecuente. Eludimos su reproducción y las numerosas referencias a la vida privada e intimidad personal de los informados o de sus familias. Sólo abordamos la dimensión política en cuanto a las calificaciones que el régimen hacia de la supuesta ideología de los informados y la pertenencia a organismos o instituciones, por otra parte ya conocidas por otras fuentes documentales, pero no las actuaciones concretas de los individuos contenidas en los informes ni las actuaciones policiales o judiciales.

7 Su padre Lucas María de Oriol y Urquijo promovió entre 1956 y 1967 la revista y editorial "Punta Europa", en el entorno católico y tradicionalista.

8 Según el Registro fue fundada por Julián Gómez del Castillo, Luis Capilla Rodríguez y Teófilo Pérez Rey, en la calle Lérida n. 80 de Madrid, donde acabó fijando su sede Zero en 1982. 
9 "A pesar de las diferentes gestiones y solicitudes que realizó la Editorial 'Zyx' para conseguir su inscripción en el registro, no lo consiguió siendo utilizado por la Administración en todo momento el silencio administrativo". Nota informativa sobre la editorial Zyx-Zero, 28 de septiembre de 1978.

10 Comunicación el 16 de enero de 1974 del Ministerio de Información al Director General de Cultura Popular con el asunto "publicaciones subversivas".

11 Pedro Ibarra desarrollaría una intensa actividad intelectual y académica como catedrático de Ciencia Política de la Universidad del País Vasco. Ignacio Cardenal Abaitua seguiria después de la experiencia en la Editorial Zero vinculado al mundo editorial protagonizando una importante labor editorial y cultural en los años setenta y ochenta en el Grupo Alfaguara-Altea-Taurus o en el Museo Thyssen.

12 Este documento con la resolución no tiene fecha e iba dirigido al registro de Empresas Editoriales por el Ministerio de Información. Una nota a mano dice "no cursado", sin que se desvelen los motivos de interrupción del proceso de cancelación. Otro documento referente a la cancelación de la empresa está fechado el 3 de junio de 1970.
$13 A B C 3$ de julio de 1965.

14 Escritura de constitución ante el notario Alberto Ballarin de Madrid.

15 Aumentó el capital social a 505.000 pesetas, emitiendo 255 acciones, el 29 de noviembre de 1967. Escritura de ampliación de capital.

16 Asociación internacional de escritores de larga trayectoria basada, entre otros principios de defensa del escritor, en la libertad de expresión. PEN (Poesía, Ensayo, Novela).

17 La Sociedad Editorial de Escritores SA (SEDE) solicitó la inscripción el 6 de abril de 1967. Estaba formada por 16 miembros, escritores, intelectuales y catedráticos de Universidad. Estaba presidida por Fernando Chueca, y como vocales figuraban Martí Zaro, Tovar, Prados y Maravall. También eran socios Ridruejo, Laín Entralgo, Sergio Vilar o Luis Felipe Vivanco.

18 Escritura de constitución el 3 de octubre de 1967 ante el notario Pastor Ridruejo, relacionado con la democracia cristiana. Ese mismo día otra escritura concedía poderes al Consejero-Delegado, Ignacio Camuñas. Veinte días más tarde se inscribía en el registro Mercantil de Madrid. Archivo INLE-REE Caja 34.

19 Archivo INLE-REE Caja 81/4. Librería Fuentetaja en Caja 252/62.

20 Archivo INLE-REE. Caja 68/3.

21 Archivo INLE-REE Caja 266/11.

22 Archivo INLE-RE. Caja 97/1.
23 Archivo INLE-REE Caja 87/5.

24 Archivo INLE-REE Caja 87/3.

25 Archivo INLE-REE Cajas 265/27 y 265/28.

26 Archivo INLE-REE Caja 128/6.

27 Archivo INLE-REE Caja 98/10.

$28 \mathrm{El}$ expediente de Estela en Archivo INLE-REE Caja 57/5. Parte del expediente está reproducido precisamente en el correspondiente a Laia, Caja 115/8. El caso de Estela y Laia merecen un estudio específico.

29 Sentencia del Tribunal Supremo. Archivo INLE-REE, Caja 67.

\section{BIBLIOGRAFÍA}

Abellán, Manuel L. (1980): Censura y creación literaria en España (1939-1976), Barcelona, Península.

Cisquella, G.-Erviti, J. L. y Sorolla, J. A. (1977): Diez años de represión cultural: la censura de libros durante la ley de prensa (1966-1976), Barcelona, Anagrama.

Ysas, Pere y Molinero, Carmen (1999): "Modernización económica e inmovilismo político", en Historia de España, siglo XX (1939-1996), dirigida por Jesús A. Martínez, Madrid, Cátedra, p. 234.

Menchero de los Ríos, M. ${ }^{a}$ Carmen (1994): La Ley Fraga y la censura editorial: 1966-1975, Universidad Complutense de Madrid. 